\title{
Ambient RF-powered Soft Nervous Materials: A Case Study
}

\author{
Khurram Karim Qureshi, ${ }^{1 *}$ Samir Mekid, ${ }^{2}$ Ahmad Saleh, ${ }^{3}$ and Mohammad S. Sharawi ${ }^{1}$ \\ ${ }^{1}$ Electrical Engineering Department, King Fahd University of Petroleum and Minerals, Dhahran 31261, KSA \\ ${ }^{2}$ Mechanical Engineering Department, King Fahd University of Petroleum and Minerals, Dhahran 31261, KSA \\ ${ }^{3}$ Department of Electrical and Computer Engineering, Oakland University, Michigan 48001, USA
}

(Received December 1, 2017; accepted April 18, 2018)

Keywords: ambient RF, nervous materials, sensors, actuators

The purpose of this work is to investigate various ways of energizing microelectromechanical systems (MEMS)-based sensors and actuators operating at low power, which can be embedded in various types of host materials without adding any extra devices as a power source. These host materials can be either soft materials or membranes, such as nylons or any low-cost polymer composite laminates. For these low-powered batteryless sensors or actuators, one of the possible power sources can be RF energy harvesters. The purpose here is to confirm the feasibility and identify the practices and critical needs of cases ranging from biomedical to general engineering applications.

\section{Introduction}

Smart nervous materials can be realized by placing sensors, actuators, and integrated circuits within the host material. These materials, which have the ability to effectively and continuously monitor various physical conditions, are of critical importance in various engineering applications. If the critical conditions are continuously monitored and controlled, problems can be detected and solved ahead of time with less downtime for repair and maintenance, leading to higher productivity and minimal energy consumption. The embedded sensors in the host materials would be used to acquire important data for the validation and improvement of design during the stage of prototyping, as well as to provide information on the performance and structural integrity of the components in service. The conventional available sensors are quite large and bulky. They are usually attached onto the surface of the host and are far from the critical locations in the material. This leads to difficulty in providing useful information from the critically distributed locations inside the material. Recently, micro-electromechanical systems (MEMS) have found many diverse applications. They are diverse from the viewpoint of functions provided by these devices and the areas in which they can be applied. These devices act as an interface between the engineering system and the physical world. Over the past few decades, the rapid evolution of state-of-the-art integrated circuits and microfabrication technology has played a major role in the development and maturation of integrated MEMS devices. The vast majority of MEMS devices are either sensors or actuators. MEMS employ *Corresponding author: e-mail: kqureshi@kfupm.edu.sa http://dx.doi.org/10.18494/SAM.2018.1830 
a wide selection of sensing and actuation schemes to carry out a varied range of specialized functions at microscale regimes, thereby effectively replacing power-consuming, area-inefficient macroscale bulk sensors, and actuator systems. ${ }^{(1)}$ Energy harvesters are considered to be a very promising and fast growing technology that can be employed as one of the feasible power supply choices for the development of embedded systems. Hitherto, many research articles have been written on this topic. ${ }^{(1-13)}$ This technology enables the development of wireless sensors employed at locations difficult to reach with conventional battery-powered designs. An energy-harvesting power supply enables the design of a sensor system with a range of 40-60 $\mathrm{m}$ and a lifespan of around 5-10 years. The energy-harvesting systems should be able to achieve perpetual operation by ensuring that the harvested energy meets or exceeds the energy requirement of the sensor system during its entire span of operation. To realize an efficient and robust energy-harvesting system, energy management is a very critical issue. Therefore, we first must determine the power output from the energy-harvesting system. The various types of energy harvesters are based on solar power, wind, external heat differentials, vibration, and piezoelectric and RF energies. In all of the above-mentioned systems, solar power is the most efficient and provides a power density of $100 \mathrm{~mW} / \mathrm{cm}^{3}$. However, the biggest demerit of this harvester is that its efficiency is very low if the sensor is located inside a building. On the other hand, the RF energy harvester provides a power density of up to $40 \mu \mathrm{W} / \mathrm{cm}^{2}$ if within $10-15 \mathrm{~m}$ of the sensor network. The harvested average dc power of the RF energy harvester can be expressed as ${ }^{(5)}$

$$
P_{a v}=P_{T X}-L+G_{R X}+G_{T X}+\eta_{R F-d c},
$$

where $P_{T X}$ is the transmitted power of the source, $G_{R X}$ is the gain of the receiving antenna, $G_{T X}$ is the gain of the transmitting antenna, and $\eta_{R F-d c}$ represents the efficiency of the RF-dc conversion circuit. $L$ denotes the propagation loss of the radiated signal and can be expressed as

$$
\begin{gathered}
L=F+18 \log \left[\left(17 h+R^{2}\right) / 17 h\right], \\
F=\left(4 \pi R / \lambda_{o}\right),
\end{gathered}
$$

where $F$ is the free space path loss, $h$ is the height of the source, $R$ is the distance from the source and $\lambda_{o}$ is the wavelength.

In recent years, the telecommunications sector and internet services have seen a boon in the Kingdom of Saudi Arabia. Therefore, many players in the market, such as Saudi Telecommunication Company (STC), Mobily, and Zain, with different market shares are operating in the kingdom. These companies have laid a huge infrastructure all over the kingdom. This infrastructure provides an opportunity for tapping this great resource at hand. Numerous spectral surveys, which measure the ambient RF power levels, have been reported in the literature. However, none have been performed or reported for the eastern coast of Saudi Arabia, to the best of our knowledge. In this work, we report the ambient RF survey performed on the campus of King Fahd University of Petroleum and Minerals (KFUPM) situated in Dhahran in the eastern province of the Kingdom of Saudi Arabia, where a large number of radio towers have been erected by mobile service providers. In the next section, we elaborate on the experimental RF checks performed on the KFUPM campus. 


\section{Experiment}

To quantify the RF power levels present in the eastern province of Saudi Arabia, we started with the measurements on our university campus. The survey was performed within the spectrum of the ultrahigh-frequency (UHF) range of $0.3-3 \mathrm{GHz}$. This range covers the GSM$900 \mathrm{MHz}, \mathrm{GSM}-1800 \mathrm{MHz}$ and 3G Long-Term-Evolution (LTE) signals emitted by the radio towers. Various radio towers were selected on campus for the survey at different locations. For the sake of traceability and for future reference, the time stamps and the global positioning system (GPS) coordinates were recorded. The mobile phone usage varies throughout the day and thus RF ambient energy is time dependent. Therefore, two sets of measurements were taken: one at around $11 \mathrm{AM}$ and the other at $8 \mathrm{PM}$ to check the range of radio frequencies present over $24 \mathrm{~h}$. Figure 1 shows the experimental setup used to measure the RF spectrum. The setup consists of a horn antenna and a broadband spectrum analyzer. Because the power density from the RF sources is quite limited, we must use a very high gain antenna for all frequencies of interest. The horn antenna used for the measurements covers the frequency range from 1 to $18 \mathrm{GHz}$. It exhibits a typical gain of $11 \mathrm{~dB}$ with a voltage standing wave ratio (VSWR) of 1:1.5 for linear polarization. The antenna factor is around $25 \mathrm{~dB} / \mathrm{m}$ with the crosspolarization isolation of about $30 \mathrm{~dB}$. The field strength measurements are carried out with the help of an Agilent FieldFox RF spectrum analyzer. The analyzer operates over the range from $5 \mathrm{kHz}$ to $26.5 \mathrm{GHz}$ with a resolution bandwidth of $1 \mathrm{~Hz}-25 \mathrm{MHz}$. The measurements are taken while using the maximum hold function of the RF spectrum analyzer. For each set of measurements, more than $1 \mathrm{~min}$ is allocated to allow for more than five sweeps across the entire selected frequency range. For all the measurements, the resolution bandwidth is chosen to be $100 \mathrm{kHz}$, and the internal amplifier is turned on for amplification. Moreover, during the measurements, the radio towers are within $8-10 \mathrm{~m}$ of the measurement setup.

\section{Results and Discussion}

Figure 2 shows the map of the KFUPM campus where the survey was performed. The six circles on the map show the locations where the measurements were taken. Figures 3-8 show
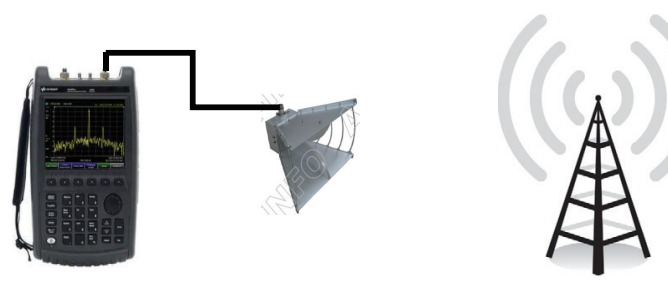

Fig. 1. (Color online) Experimental setup of ambient RF measurements.

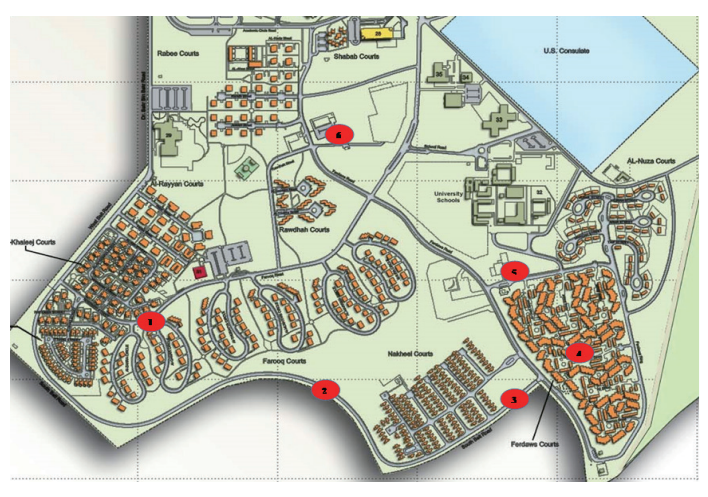

Fig. 2. (Color online) Map of KFUPM campus with six red dots showing the locations where ambient RF measurements were taken. 
the spectra obtained at six different locations on the campus. All these figures very clearly show the presence of GSM-900 MHz and GSM-1800 MHz signals from the mobile towers. The measurements also confirm the presence of LTE bands covering 2.1, 2.3, and 2.6 GHz. Figure 3 shows the spectrum obtained at location 1 (semicrowded) with GPS coordinates of $\mathrm{N} 26^{\circ}$ $17^{\prime} 45.5^{\prime \prime}$ and E $050^{\circ} 08^{\prime} 34.4^{\prime \prime}$. From the spectrum profile, it is clear that at the frequencies of 950 and $1850 \mathrm{MHz}$, the peak signal power is $-25 \mathrm{dBm} / \mathrm{Hz}$. Similarly, for the same location at the frequencies of 2.1 and $2.35 \mathrm{GHz}$, the peak power observed is also around $-25 \mathrm{dBm} / \mathrm{Hz}$. The peak powers at this location are similar for the measurements taken during the day and night. Figure 4 shows the measurements at location 2 (open) with GPS coordinates of N 26 17'35.3' E $050^{\circ} 08^{\prime} 29.2^{\prime \prime}$. At this location, the peak spectral power is around $-30 \mathrm{dBm} / \mathrm{Hz}$ for frequencies at $950 \mathrm{MHz}$ and $2.6 \mathrm{GHz}$. Again, there is not much difference in the spectral profile between the day and night measurements. Figure 5 shows the measurements at location 3 (open) with GPS coordinates of $\mathrm{N} 26^{\circ} 17^{\prime} 31.5^{\prime}$ ' E $050^{\circ} 08^{\prime} 57.3$ ". Here, the peak power densities are around $-20,-30,-23$, and $-30 \mathrm{dBm} / \mathrm{Hz}$ at $950 \mathrm{MHz}, 1850 \mathrm{MHz}, 2.1 \mathrm{GHz}$, and $2.35 \mathrm{GHz}$, respectively. Again, not much difference is observed between the day and night measurements. Figure 6 shows the measurements taken at location 4 (crowded) with GPS coordinates of $\mathrm{N} 26^{\circ}$ 17 '41.6" E $050^{\circ} 09^{\prime} 16.9^{\prime \prime}$. The spectrum shows that the power density of the radio signals is stronger during the night than the day. The peak power densities are around $-23,-24,-23$, and $-30 \mathrm{dBm} / \mathrm{Hz}$ at $950 \mathrm{MHz}, 1850 \mathrm{MHz}, 2.1 \mathrm{GHz}$, and $2.35 \mathrm{GHz}$ for the day measurements,

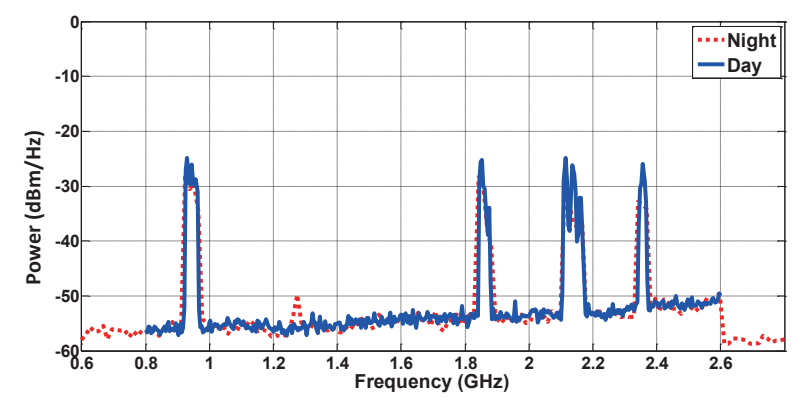

Fig. 3. (Color online) RF power density measurements at location $1\left(\mathrm{~N} 26^{\circ} 17^{\prime} 45.5^{\prime \prime}\right.$ and $\mathrm{E}$ $\left.050^{\circ} 08^{\prime} 34.4^{\prime \prime}\right)$.

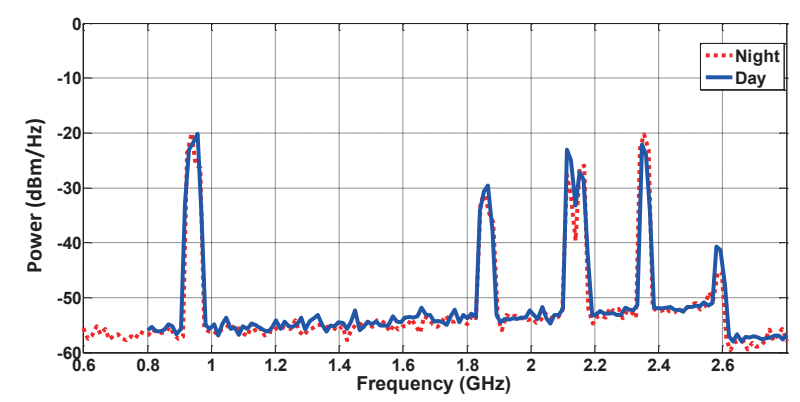

Fig. 5. (Color online) RF power density measurements at location $3\left(\mathrm{~N} 26^{\circ} 17^{\prime} 31.5^{\prime \prime} \mathrm{E} 050^{\circ}\right.$ 08'57.3').

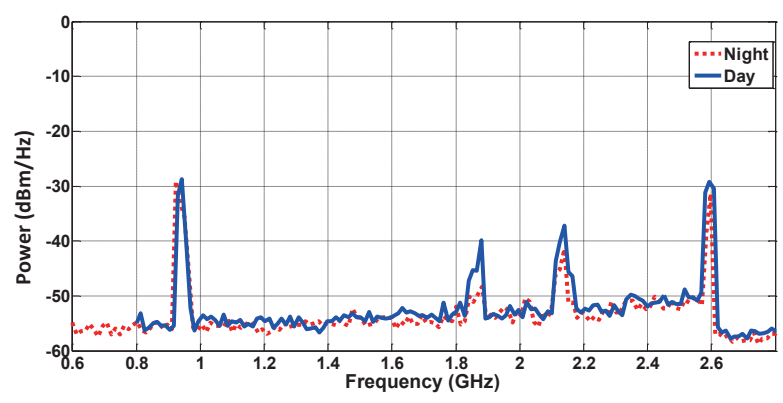

Fig. 4. (Color online) RF power density measurements at location $2\left(\mathrm{~N} 26^{\circ} 17^{\prime} 35.3^{\prime \prime}\right.$ E $050^{\circ}$ 08'29.2").

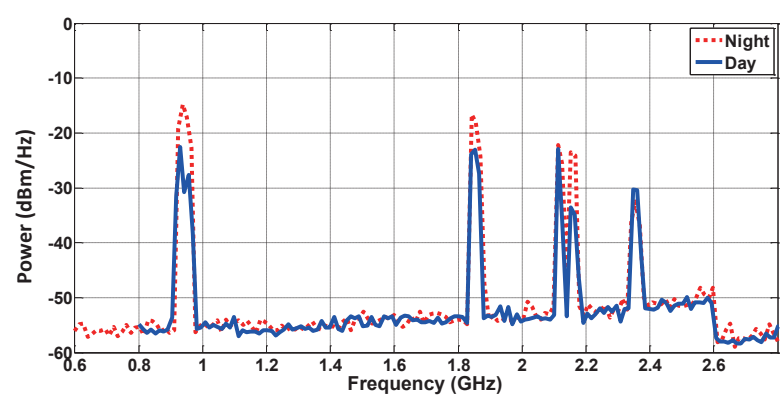

Fig. 6. (Color online) RF power density measurements at location $4\left(\mathrm{~N} \mathrm{26} 6^{\circ} 17^{\prime} 41.6^{\prime \prime}\right.$ E $050^{\circ}$ 09'16.9'). 
respectively. However, the peak power densities are -15 and $-17 \mathrm{dBm} / \mathrm{Hz}$ for 950 and 1850 $\mathrm{MHz}$ bands for the night measurements. Figure 7 shows the measurements taken at location 5 (semicrowded) with GPS coordinates of N 26 17'51.4" E $050^{\circ} 09^{\prime} 09.8^{\prime \prime}$. The peak power densities are around $-25,-27,-23,-37$, and $-32 \mathrm{dBm} / \mathrm{Hz}$ at $950 \mathrm{MHz}, 1850 \mathrm{MHz}, 2.1 \mathrm{GHz}, 2.35$ $\mathrm{GHz}$ and $2.6 \mathrm{GHz}$ for the day measurements, respectively. The night measurements show peak powers of $-32,-47$, and $-45 \mathrm{dBm} / \mathrm{Hz}$ at $2.1,2.35$, and $2.6 \mathrm{GHz}$, respectively. Figure 8 shows the measurements taken at location 6 (open) with GPS coordinates of $\mathrm{N} 26^{\circ} 18^{\prime} 03.8^{\prime \prime} \mathrm{E} 050^{\circ}$ 08'50.7'. Here, the peak power densities are around $-23,-34,-42$, and $-37 \mathrm{dBm} / \mathrm{Hz}$ at 950 $\mathrm{MHz}, 1850 \mathrm{MHz}, 2.1 \mathrm{GHz}$ and $2.35 \mathrm{GHz}$ for the day measurements, respectively. The night measurements are essentially the same as the day measurements for this location. The results for day measurements are shown in Table 1 and those for night measurements in Table 2 for the sake of comparison.

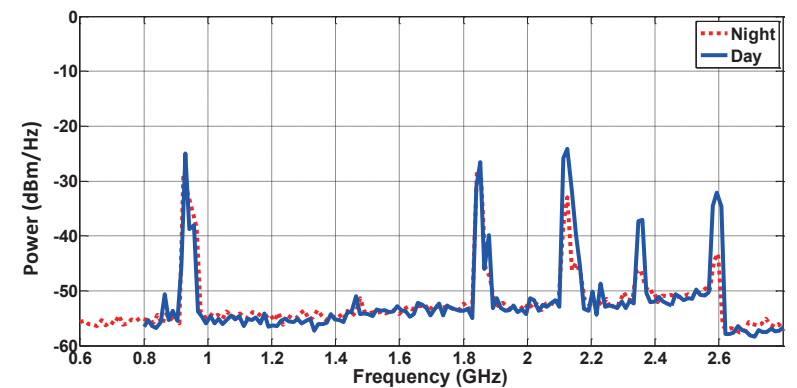

Fig. 7. (Color online) RF power density measurements at location $5\left(\mathrm{~N} 26^{\circ} 17^{\prime} 51.4^{\prime \prime} \mathrm{E} 050^{\circ}\right.$ 09'09.8').

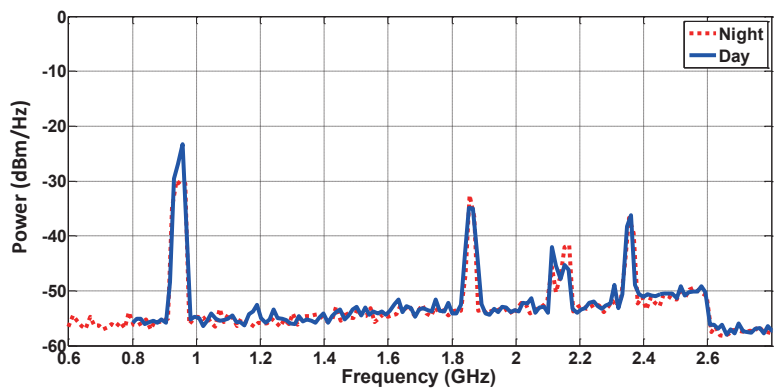

Fig. 8. (Color online) RF power density

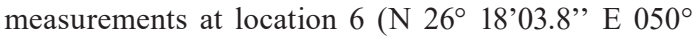
08 '50.7').

Table 1

Peak power densities for various RF signals on KFUPM campus during the day.

\begin{tabular}{lccccc}
\hline Location & GSM $850 \mathrm{MHz}$ & GSM $1850 \mathrm{MHz}$ & LTE $2.1 \mathrm{GHz}$ & LTE $2.35 \mathrm{GHz}$ & LTE $2.6 \mathrm{GHz}$ \\
\hline Loc $1(\mathrm{SC})$ & $-25 \mathrm{dBm} / \mathrm{Hz}$ & $-25 \mathrm{dBm} / \mathrm{Hz}$ & $-24 \mathrm{dBm} / \mathrm{Hz}$ & $-25 \mathrm{dBm} / \mathrm{Hz}$ & - \\
Loc 2 $(\mathrm{O})$ & $-29 \mathrm{dBm} / \mathrm{Hz}$ & $-40 \mathrm{dBm} / \mathrm{Hz}$ & $-38 \mathrm{dBm} / \mathrm{Hz}$ & - & $-29 \mathrm{dBm} / \mathrm{Hz}$ \\
Loc 3 $(\mathrm{O})$ & $-20 \mathrm{dBm} / \mathrm{Hz}$ & $-30 \mathrm{dBm} / \mathrm{Hz}$ & $-23 \mathrm{dBm} / \mathrm{Hz}$ & $-21 \mathrm{dBm} / \mathrm{Hz}$ & $-41 \mathrm{dBm} / \mathrm{Hz}$ \\
Loc $4(\mathrm{C})$ & $-22 \mathrm{dBm} / \mathrm{Hz}$ & $-23 \mathrm{dBm} / \mathrm{Hz}$ & $-22 \mathrm{dBm} / \mathrm{Hz}$ & $-30 \mathrm{dBm} / \mathrm{Hz}$ & - \\
Loc 5 $(\mathrm{SC})$ & $-25 \mathrm{dBm} / \mathrm{Hz}$ & $-27 \mathrm{dBm} / \mathrm{Hz}$ & $-24 \mathrm{dBm} / \mathrm{Hz}$ & $-37 \mathrm{dBm} / \mathrm{Hz}$ & $-32 \mathrm{dBm} / \mathrm{Hz}$ \\
Loc 6 (O) & $-23 \mathrm{dBm} / \mathrm{Hz}$ & $-34 \mathrm{dBm} / \mathrm{Hz}$ & $-42 \mathrm{dBm} / \mathrm{Hz}$ & $-36 \mathrm{dBm} / \mathrm{Hz}$ & - \\
\hline
\end{tabular}

C: crowded; S: semicrowded; O: open

Table 2

Peak power densities for various RF signals on KFUPM campus during the night.

\begin{tabular}{lccccc}
\hline Location & GSM $850 \mathrm{MHz}$ & GSM $1850 \mathrm{MHz}$ & LTE 2.1 GHz & LTE 2.35 GHz & LTE 2.6 GHz \\
\hline Loc 1 (SC) & $-26 \mathrm{dBm} / \mathrm{Hz}$ & $-28 \mathrm{dBm} / \mathrm{Hz}$ & $-28 \mathrm{dBm} / \mathrm{Hz}$ & $-30 \mathrm{dBm} / \mathrm{Hz}$ & $-28 \mathrm{dBm} / \mathrm{Hz}$ \\
Loc 2 (O) & $-30 \mathrm{dBm} / \mathrm{Hz}$ & $-45 \mathrm{dBm} / \mathrm{Hz}$ & $-40 \mathrm{dBm} / \mathrm{Hz}$ & - & $-29 \mathrm{dBm} / \mathrm{Hz}$ \\
Loc 3 (O) & $-20 \mathrm{dBm} / \mathrm{Hz}$ & $-32 \mathrm{dBm} / \mathrm{Hz}$ & $-27 \mathrm{dBm} / \mathrm{Hz}$ & $-20 \mathrm{dBm} / \mathrm{Hz}$ & $-43 \mathrm{dBm} / \mathrm{Hz}$ \\
Loc 4 (C) & $-15 \mathrm{dBm} / \mathrm{Hz}$ & $-17 \mathrm{dBm} / \mathrm{Hz}$ & $-22 \mathrm{dBm} / \mathrm{Hz}$ & $-32 \mathrm{dBm} / \mathrm{Hz}$ & - \\
Loc 5 (SC) & $-27 \mathrm{dBm} / \mathrm{Hz}$ & $-27 \mathrm{dBm} / \mathrm{Hz}$ & $-32 \mathrm{dBm} / \mathrm{Hz}$ & $-45 \mathrm{dBm} / \mathrm{Hz}$ & $-43 \mathrm{dBm} / \mathrm{Hz}$ \\
Loc 6 (O) & $-30 \mathrm{dBm} / \mathrm{Hz}$ & $-32 \mathrm{dBm} / \mathrm{Hz}$ & $-42 \mathrm{dBm} / \mathrm{Hz}$ & $-38 \mathrm{dBm} / \mathrm{Hz}$ & -
\end{tabular}

C: crowded; S: semicrowded; O: open 
Table 1 shows the peak power spectral densities for various RF signals at 6 different locations on the KFUPM campus during the day. The maximum peak spectral density was measured to be $-20 \mathrm{dBm} / \mathrm{Hz}$ at $850 \mathrm{GHz}$ at location 3, whereas the maximum peak spectral density of $-23 \mathrm{dBm} / \mathrm{Hz}$ for the GSM-1850 MHz signal was measured at location 4 . As far as the LTE signals are concerned, the maximum peak spectral density of $-21 \mathrm{dBm} / \mathrm{Hz}$ was observed at LTE $2.35 \mathrm{GHz}$. The maximum peak spectral density of $-22 \mathrm{dBm} / \mathrm{Hz}$ for LTE $2.1 \mathrm{GHz}$ was observed at location 4. For LTE $2.6 \mathrm{GHz}$, the maximum peak spectral density of $-29 \mathrm{dBm} / \mathrm{Hz}$ was observed at location 2. For the day measurements, the maximum peak power achieved was $-20 \mathrm{dBm} / \mathrm{Hz}$, which corresponds to $10 \mu \mathrm{W}$.

Table 2 shows the peak power spectral densities for various RF signals at 6 different locations on the KFUPM campus during the night at 8 PM. The maximum peak spectral density was measured to be $-15 \mathrm{dBm} / \mathrm{Hz}$ at $850 \mathrm{GHz}$ at location 4 , whereas the maximum peak spectral density of $-17 \mathrm{dBm} / \mathrm{Hz}$ for the GSM-1850 MHz signal was measured at location 4 . As far as the LTE signals are concerned, the maximum peak spectral density of $-20 \mathrm{dBm} / \mathrm{Hz}$ was observed for the LTE $2.35 \mathrm{GHz}$ signal at location 3. The maximum peak spectral density of -22 $\mathrm{dBm} / \mathrm{Hz}$ for the LTE $2.1 \mathrm{GHz}$ signal was observed at location 4. For the LTE $2.6 \mathrm{GHz}$ signal, the maximum peak spectral density of $-28 \mathrm{dBm} / \mathrm{Hz}$ was observed at location 1 . For the night measurements, the maximum peak power achieved was $-15 \mathrm{dBm} / \mathrm{Hz}$, which corresponds to $31.6 \mu \mathrm{W}$.

From the literature, ${ }^{(1-6)}$ it is quite clear that the conversion efficiency from RF-dc circuits is only around $10-30 \%$ owing to low input power levels $(-30$ to $-20 \mathrm{dBm})$. However, the harvested power can generate around 1.8-4.0 V with a total converted power of about $100 \mu \mathrm{W}$. This power level is considered good enough to operate battery-assisted sensors and actuators over a duration of more than 5 years. The harvested RF signal will be further enhanced as the antenna gain and energy density of the surrounding environment improve. Our ambient RF survey has clearly shown that one of its possible applications can be to power MEMS devices embedded in host soft materials. ${ }^{(14)}$ The host material is usually composed of different layers of composites. They include carbon-fiber-reinforced polymer (CFRP) or glassfiber-reinforced polymer (GFRP). These materials are utilized owing to their superior flexibility, low thermal conductivity, and high thermal stability. The MEMS sensors and actuators are embedded in the composite laminate prepreg layers during their fabrication. The laminate consists of around 20-25 individual layers. The thickness of the sensors/actuators is around 6-7 layers. In these layers, an area corresponding to the dimensions of the sensor is cut out to avoid surface steps during the lamination process. Finally, the host material with the embedded sensors is processed under vacuum in an autoclave and cured at around $120{ }^{\circ} \mathrm{C}$ for a 3 to $4 \mathrm{~h} .{ }^{(15)}$ For the various MEMS-based devices, the power requirement is around $10-20 \mu \mathrm{W}$, which can be easily provided by the freely available ambient RF energy harvesting technology. Our ambient RF survey has clearly shown the possibility of efficiently utilizing ambient RF energy harvesting for powering the MEMS-based embedded sensors and actuators in different materials or membranes. A recently reported ${ }^{(16)}$ low-power-consumption rotary actuator can be efficiently powered by this widely available ambient RF energy. These RF powered MEMS-based embedded devices can be part of a telemetry system whereby they remotely measure some 
physical parameters and send the information back to a central processing center for further action. Some of the ambient RF power can be used to charge the battery and the remaining power can be used to send the information to the processing center.

\section{Conclusions}

We proposed a feasibility study for the development of soft nervous materials driven by freely available ambient wireless RF power energy without the need of batteries. The promising results showed that there is a huge potential to use this ambient RF energy source for powering embedded sensors in soft nervous materials. For MEMS-based sensors and actuators, the power requirement is around $10-20 \mu \mathrm{W}$, which can be easily provided by harvesting the widely available ambient RF energy.

\section{Acknowledgments}

The authors would like to acknowledge the support provided by King Abdulaziz City for Science and Technology (KACST) through King Fahd University of Petroleum and Minerals (KFUPM) for funding this project (11-ADV2133-04) as part of the National Science, Technology, and Innovation Plan.

\section{References}

1 S. Kim, R. Vyas, and J. Bito: Proc. IEEE 102 (2014) 1649.

2 M. Pinuela, P. Mitcheson, and S. Lucyszn: IEEE Trans. Microwave Theory Tech. 61 (2013) 2715.

3 X. Lu, P. Wang, D. Niyato, D. Kin, and Z. Hau: IEEE Commum. Surv. Tutorials 17 (2014) 757.

4 J. Li, K. Xiong, P. Fan, and Z. Zhong: IEEE Access 5 (2017) 9348.

5 T. Le, K. Mayaram, and T. Fiez: IEEE J. Sol-State Circuits 43 (2008) 1287.

6 H. Visser and R. J. M. Vullers: Proc. IEEE 101 (2013) 1410.

7 F. Yildiz: J. Technol. Studies 35 (2009) 40.

8 R. Prasad, S. Devasenapathy, V. S. Rao, and J. Vazifehdan: IEEE Commun. Surv. Tutorials 16 (2014) 195.

9 R. Shigeta, T. Sasaki, D. M. Quan, Y. Kamahara, R. J. Vyas, M. M. Tentzeris, and T. Asami: IEEE Sens. J. 13 (2013) 2973.

10 W. C. Brown: IEEE Trans. Microwave Theory Tech. 32 (1984) 1230.

11 A. Kurs, A. Karalis, R. Moffat, J. D. Joannopolous, P. Fisher, and M. Soljacic: Science 317 (2007) 83.

12 H. Shoki: Proc. IEEE 101 (2013) 1312.

13 R. J. Vyas, B. S. Cook, Y. Kawahara, and M. M. Tentzeris: IEEE Trans. Microwave Theory Tech. 61 (2013) 2491.

14 W. Lang, F. Jakobs, E. Tolstosheeva, H. Sturm, A. Ibragimov, A. Kesel, D. Lehmhus, and U. Dicke: Sens. Actuators, A 171 (2011) 3.

15 M. Schwerter, M. L. Schadoel, S. Buttgenbach, A. Dietzel, C. Behr, M. Sinapius, and P. Wierach: Proc. IEEE Sensors (2014).

16 L. Manfredi, Y. Huan, and A. Cuschieri: Smart Mater. Struct. 26 (2017) 115003. 


\section{About the Authors}

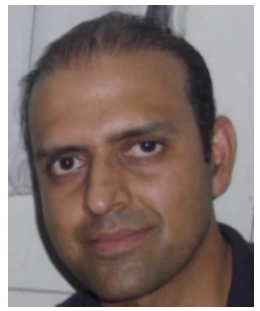

Khurram Karim Qureshi received his B.Sc. degree with honors in electrical engineering from the University of Engineering and Technology, Pakistan, in 1999 and Ph.D. in electrical engineering from the Hong Kong Polytechnic University in 2006. He is currently an associate professor with the Electrical Engineering Department of King Fahd University of Petroleum and Minerals (KFUPM). His research interests include optical signal processing, fiber lasers and fiber Sensors. He is a senior member of Institute of Electrical and Electronics Engineering (IEEE), USA. He has published more than 50 journal and conference papers along with three US patents issued to his credit.

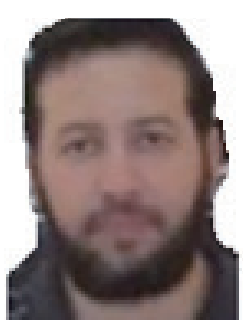

Samir Mekid is a Chartered Engineer registered in London, UK, by IMECHE and professor of mechanical engineering at the Department of Mechanical Engineering, KFUPM. Precision machine design, instrumentation, and manufacturing are his main research areas. Prior to joining KFUPM, he served as lecturer (assistant professor) at The University of Manchester, UK. Samir has published more than 100 research papers, two books from CRC and Springer and about two dozens patents.

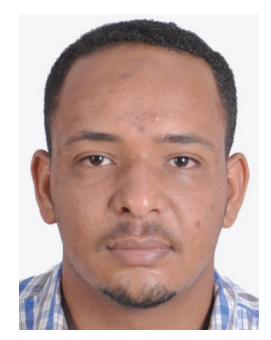

Ahmad Saleh is currently pursuing his Ph.D. degree in the Department of Electrical and Computer Engineering, Oakland University, Michigan, USA. Before that, he completed his M.Sc. degree at KFUPM in 2016.

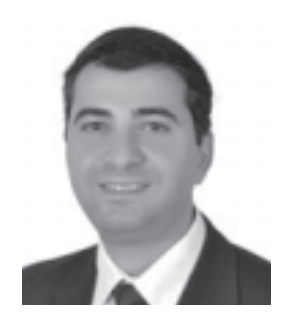

Mohammad S. Sharawi received his Ph.D. degree in RF systems engineering from Oakland University, Oakland, MI, USA, in 2006. He is currently a professor of electrical engineering with KFUPM, Dhahran, Saudi Arabia. He is an Institute of Engineering and Technology (IET) Fellow and a senior member of IEEE. His current research interests include printed multipleinput-multiple-output antenna systems, miniaturized printed antennas and antenna arrays, active integrated antennas, reconfigurable antennas, microwave circuits and electronics, millimeter-wave antennas and antenna arrays, and applied electromagnetics. 